\title{
Light Response of Three Water-Soluble Mn' PhotoCORMs: Spectroscopic Features and CO Release Investigation
}

\author{
Vitor C. Weiss, ${ }^{a, b}$ André L. Amorim, ${ }^{a}$ Fernando R. Xavier, ${ }^{c}$ Adailton J. Bortoluzzi, ${ }^{a}$ \\ Ademir Neves ${ }^{a}$ and Rosely A. Peralta ${ }^{\circledR} * a$
}

${ }^{a}$ Laboratório de Bioinorgânica e Cristalografia (LABINC), Departamento de Química, Universidade Federal de Santa Catarina, 88040-900 Florianópolis-SC, Brazil

${ }^{b}$ Instituto Federal de Educação, Ciência e Tecnologia de Santa Catarina (IFSC), Campus Florianópolis, 88020-300 Florianópolis-SC, Brazil

'Universidade do Estado de Santa Catarina (UDESC), Campus Joinville, 89219-710 Joinville-SC, Brazil

\begin{abstract}
Currently, there is great interest in the study of water-soluble metal compounds capable of releasing carbon monoxide, due to their potential therapeutic use. This paper reports the synthesis, spectroscopic characteristics and $\mathrm{CO}$ release properties of three water-soluble manganese(I) carbonyl compounds $\left[\mathrm{Mn}(\mathrm{aaz})(\mathrm{CO})_{3}\right] \mathrm{Br}(\mathbf{1}$; where aaz = 6-amino-6-methylperhydro-1,4-diazepine $)$, $\left[\mathrm{Mn}\left(\mathrm{Me}_{2} \mathrm{aaz}\right)(\mathrm{CO})_{3}\right] \mathrm{Br}\left(\mathbf{2}\right.$; where $\mathrm{Me}_{2}$ aaz = 6-amino-1,4,6-trimethyl-1,4-diazacycloheptane $)$ and $\left[\mathrm{Mn}(\operatorname{tacn})(\mathrm{CO})_{3}\right] \operatorname{Br}(\mathbf{3}$; where tacn $=1,4,7$-triazacyclononane), that can act as photoCORMs (where CORM is carbon monoxide-releasing molecule). The main aim was to propose a mechanism for the CO release. Compounds $\mathbf{1 - 3}$ are capable of releasing carbon monoxide when exposed to light $\left(\lambda_{385}\right.$ and $\left.\lambda_{410}\right)$ and thus, act as photoCORMs. The formation of a biscarbonyl intermediate was identified during the photo-release process at $\lambda_{385}$ and the quantum yields and rates of CO release were determined. The proposed CO release mechanisms involve two steps, where photo and redox processes take place, and compounds $\mathbf{1}$ and $\mathbf{2}$ exhibit a slightly different mechanism from compound 3. A good understanding of the $\mathrm{CO}$ photo-release mechanism is very important with regard to the development of more efficient compounds, particularly those intended for medical applications.
\end{abstract}

Keywords: photoCORM, manganese(I) tricarbonyl compounds, photoreactivity

\section{Introduction}

Carbon monoxide $(\mathrm{CO})$ is widely known as a silent killer, but the discovery of its beneficial features has led several research groups to use $\mathrm{CO}$ as a therapeutic agent in the past decade. ${ }^{1,2}$ Since it is a cell signaling molecule, ${ }^{3,4}$ the therapeutic properties of carbon monoxide range from anti-inflammatory and antiapoptotic to having an antiproliferation effect on malign cells..$^{5-7}$ However, the direct application of gaseous $\mathrm{CO}$ as a therapeutic agent has two major drawbacks: its high affinity towards hemoglobin ${ }^{8}$ and the uncertainties associated with its direct inhalation by patients, ${ }^{9,10}$ given a lack of control and specificity. One way to overcome these disadvantages is the use of molecular carriers, which act as prodrugs and can transport carbon monoxide into the organism in a

*e-mail: rosely.peralta@ufsc.br controlled manner, only releasing $\mathrm{CO}$ under the influence of a specific trigger. ${ }^{11-13}$

Several carriers based on organic compounds ${ }^{14,15}$ or using transition metals, such as tungsten, molybdenum, iron, ruthenium, rhenium and manganese, ${ }^{16-21}$ have been used to deliver $\mathrm{CO}$ to the organism, the latter being preferred due to the high flexibility in terms of the properties obtained from both the metal center and the organic framework. ${ }^{13}$ The correct selection of these properties is essential in the development of new metal carbonyl compounds (MCCs), ${ }^{12}$ which should preferentially be water soluble..$^{22,23}$

Among the first CO-releasing molecules are those that release carbon monoxide upon ligand exchange between the carbonyl in the first coordination sphere of the MCC and a coordinating species present in the medium studied. In the case of carbon monoxide-releasing molecule (CORM)-3, for instance, the $\mathrm{CO}$ release mechanism is highly dependent on the medium..$^{24}$ 
Photoactivation of the MCCs seems to be the most attractive trigger, considering the temporal and spatial control of the carbon monoxide release. Metal carbonyl compounds such as these, which are of great importance, are termed photoCORMs. ${ }^{25,26}$

In this regard, several research groups have been studying photoCORMs. They present a wide array of characteristics, such as the lipophilic properties of CORM-1 $\left(\mathrm{Mn}_{2}(\mathrm{CO})_{10}\right)^{27}$ and the localization of the prodrug, which can be performed by Raman microspectroscopy in the case of $\left[\mathrm{Mn}(\mathrm{tmp})(\mathrm{CO})_{3}\right]^{+}$ (tmp: tris((pyrazolyl)methane $)^{28}$ or fluorescence microscopy for $\left[\mathrm{Mn}(\mathrm{Imdansyl})(\mathrm{CO})_{3}(\right.$ phen $\left.)\right]\left(\mathrm{CF}_{3} \mathrm{SO}_{3}\right)^{29}$ (Imdansyl: dansylimidazole).

Despite the recent advances, the CO release mechanism associated with manganese photoCORMs, which have more than one carbonyl group in the first coordination sphere, are not commonly explored in depth, one counterexample being the studies conducted by the Kurz and co-workers. ${ }^{30,31}$ In this context, we report herein three new manganese photoCORMs that show desirable properties as carbonylcontaining prodrugs, such as high stability and water solubility, as well as some mechanistic insights regarding the carbon monoxide release process.

The synthesis and characterization of the three carbonyl compounds mentioned above, $\left[\mathrm{Mn}(\mathrm{aaz})(\mathrm{CO})_{3}\right] \mathrm{Br}$ (1; where aaz = 6-amino-6-methylperhydro-1,4-diazepine), $\left[\mathrm{Mn}\left(\mathrm{Me}_{2} \mathrm{aaz}\right)(\mathrm{CO})_{3}\right] \mathrm{Br}\left(2\right.$; where $\mathrm{Me}_{2} \mathrm{aaz}=6$-amino1,4,6-trimethyl-1,4-diazacycloheptane) and $[\mathrm{Mn}(\operatorname{tacn})$ $\left.(\mathrm{CO})_{3}\right] \mathrm{Br}(3$; where tacn $=1,4,7$-triazacyclononane $)$ (Figure 1) are reported herein. All compounds were fully characterized using standard techniques including infrared (IR), ultraviolet-visible (UV-Vis) and nuclear magnetic resonance (NMR) spectroscopies, electrochemistry, $\mathrm{X}$-ray crystallography and electrospray ionization-mass spectrometry (ESI-MS). The stability and the $\mathrm{CO}$ release were monitored, using an array of techniques, and the mechanisms for the $\mathrm{CO}$ release are proposed.

\section{Experimental}

\section{General procedures}

All solvents were dried with molecular sieves $(4 \AA)$ for $72 \mathrm{~h}$ prior to use unless otherwise specified. The solutions were degassed either by freeze pump thaw cycles or by argon flux. The ligands aaz and $\mathrm{Me}_{2}$ aaz were synthesized analogously to previous published procedures, ${ }^{32,33}$ while tacn was bought from Sigma-Aldrich (São Paulo, Brazil) and used without further purification. The $\left[\mathrm{Mn}(\mathrm{CO})_{5} \mathrm{Br}\right]$ and lyophilized human hemoglobin were purchased from Sigma-Aldrich (São Paulo, Brazil).

\section{Physical measurements}

Elemental analysis was performed on a PerkinElmer (Model 2400 Series II) CHNS/O analyzer coupled with a PerkinElmer scale (Model Autobalance AD 6000) using 5.0 grade helium and 6.0 grade oxygen. The infrared spectra were obtained on a PerkinElmer Spectrum 100 FT-IR spectrophotometer in the range of 4000 to $450 \mathrm{~cm}^{-1}$. The solid samples were analyzed by attenuated total reflectance (ATR) using the UATR module and the solubilized samples were homogenized with dried $\mathrm{KBr}$ powder. NMR spectroscopy was carried out on a Bruker Ascend400 Varian FT-NMR $400 \mathrm{MHz}$ setup using dimethyl sulfoxide (DMSO- $d_{6}$ ) as the solvent, at $25^{\circ} \mathrm{C}$. Chemical shifts were referenced to tetramethylsilane (TMS, $\delta 0.000 \mathrm{ppm}$ ). For the kinetic experiments, ${ }^{1} \mathrm{H}$ NMR data were acquired at selected time intervals during $1 \mathrm{~h}$ of light irradiation at $385 \mathrm{~nm}$. ESI-MS was performed on an Amazon-Ions Trap MS system in spectroscopic grade acetonitrile solution with an approximate concentration of $500 \mathrm{ppb}$ and estimated flow of $180 \mu \mathrm{L} \mathrm{min}^{-1}$. The temperature of the capillary was maintained at $180-200{ }^{\circ} \mathrm{C}$ and the capillary voltage was between -400 and $-500 \mathrm{~V}$. The redox behavior of the title compounds was investigated by cyclic and square wave voltammetry using a BAS model Epsilon potentiostat (Bioanalytical Systems, Inc.) in spectroscopic grade acetonitrile with concentrations of $1.00 \times 10^{-4} \mathrm{~mol} \mathrm{~L}^{-1}$, under argon atmosphere. Tetrabutylammonium hexafluorophosphate $\left(\mathrm{TBAPF}_{6}\right)$ with a concentration of $0.1 \mathrm{~mol} \mathrm{~L}^{-1}$ was used as the supporting electrolyte. The following electrodes were used: $\mathrm{Ag} / \mathrm{Ag}^{+}$(reference) and platinum (work and auxiliary). The ferrocene/ferrocenium pair $\left(\mathrm{Fc} / \mathrm{Fc}^{+}\right)$was used as an internal reference and the potentials were referenced versus the normal hydrogen electrode (NHE). ${ }^{34}$

Further details on the single crystal X-ray diffraction (XRD) analysis, density functional theory (DFT) and
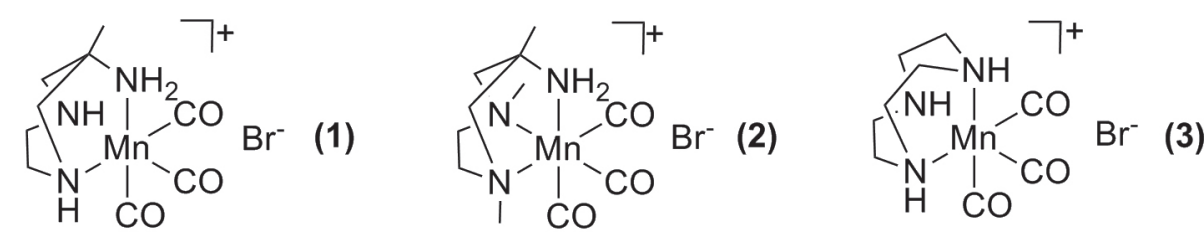

Figure 1. Schematic representation of the manganese(I) carbonyl compounds: $\left[\mathrm{Mn}(\mathrm{aaz})(\mathrm{CO})_{3}\right] \mathrm{Br}(\mathbf{1}) ;\left[\mathrm{Mn}\left(\mathrm{Me}{ }_{2}\right.\right.$ aaz $\left.)(\mathrm{CO})_{3}\right] \mathrm{Br}(\mathbf{2})$ and $\left[\mathrm{Mn}(\operatorname{tacn})(\mathrm{CO})_{3}\right] \mathrm{Br}(\mathbf{3})$. 
time-dependent density functional theory (TD-DFT) calculations, $\mathrm{CO}$ release and hemoglobin assay are provided in the Supplementary Information.

\section{CO release assay}

To determine the stability of the organometallic compounds, the charge transfer bands were monitored over a 14-h period in the absence of light. The compounds were solubilized in $\mathrm{H}_{2} \mathrm{O}$ with concentrations of $1.00 \times 10^{-3} \mathrm{~mol} \mathrm{~L}^{-1}$ and subsequently diluted to $6.00 \times 10^{-4} \mathrm{~mol} \mathrm{~L}^{-1}$.

After investigating the stability in solution, the quantum yield of $\mathrm{CO}$ release was determined by monitoring the decrease of the charge transfer band, at around 300 and $400 \mathrm{~nm}$. The ferrioxalate actinometry assay ${ }^{19}$ was used to determine the photo flow of the light source used.

The light sources employed to perform the $\mathrm{CO}$ release assays were two sets of light emitting diodes (LEDs), with the following wavelengths: $\lambda_{385}=385 \pm 10 \mathrm{~nm}$ (photon flux $=1.13 \times 10^{-8}$ Einstein s$^{-1}$ ) and $\lambda_{410}=410 \pm 5 \mathrm{~nm}$ (photon flux $=1.03 \times 10^{-8}$ Einstein $\mathrm{s}^{-1}$ ). The distance between the analyte and the lamp was set at $3.0 \mathrm{~cm}$, where the light source was arranged perpendicularly to the sample.

\section{Hemoglobin assay}

A modified version of the deoxymyoglobin assay was conducted, ${ }^{35}$ using hemoglobin as the substrate. A stock solution of hemoglobin with a concentration of approximately $3.00 \times 10^{-5} \mathrm{~mol} \mathrm{~L}^{-1}(2 \mathrm{mg}, 2 \mathrm{~mL})$ was prepared by dissolving the protein in a degassed phosphate buffer saline (PBS) solution $\left(0.1 \mathrm{~mol} \mathrm{~L}^{-1}, \mathrm{pH} 7.4\right)$ to which sodium dithionite was added $(20 \mathrm{mg})$. The organometallic compounds were dissolved in water, resulting in concentrations of $2.57 \times 10^{-4} \mathrm{~mol} \mathrm{~L}^{-1}$. The measurements were performed by diluting $146 \mu \mathrm{L}$ of the MCC solution in $1 \mathrm{~mL}$ of the hemoglobin solution. The cuvettes were sealed with a Teflon stopper, preventing the loss of carbon monoxide. The samples were irradiated identically to the $\mathrm{CO}$ release assay reported previously but using only the $\lambda_{385}$ LED. In order to detect the influence of sodium dithionite on the carbon monoxide release, the samples were also analyzed without the incidence of light. The formation of $\mathrm{HbCO}$ was monitored until no further spectral changes were observed, and the amount of $\mathrm{CO}$ released was calculated, taking into consideration that $\mathrm{Hb}$ is a tetramer.

\section{Synthesis of the complexes}

All photoCORMs studied were synthesized using the standard Schlenk technique by adding $\left[\mathrm{Mn}(\mathrm{CO})_{5} \mathrm{Br}\right]$
( $0.3 \mathrm{mmol}, 82.4 \mathrm{mg}, 1$ equiv.) to a frozen $\mathrm{CH}_{3} \mathrm{CN}$ solution $(10 \mathrm{~mL})$ of the ligands $(0.3 \mathrm{mmol}, 38.7 \mathrm{mg}$ (aaz or tacn) and $47.1 \mathrm{mg}$ ( $\left.\mathrm{Me}_{2} \mathrm{aaz}\right), 1$ equiv.). After reaching ambient temperature the resulting solution was refluxed for $12 \mathrm{~h}$ under inert atmosphere and dim light conditions. After this time, the resulting mixtures were cooled to room temperature and the precipitates were collected by vacuum filtration and washed three times with cold $\mathrm{CH}_{2} \mathrm{Cl}_{2}$, resulting in pale yellow powders. Yellow crystals of $\mathbf{1}$ and $\mathbf{3}$ were obtained by slow evaporation from ethanol solutions at $20{ }^{\circ} \mathrm{C}$. Good quality crystals of $\left[\mathrm{Mn}\left(\mathrm{Me}_{2} \mathrm{aaz}\right)(\mathrm{CO})_{3}\right]^{+}$ could only be obtained by exchanging the bromide counterion for nitrate, by adding one equivalent of $\mathrm{AgNO}_{3}$ to an acetonitrile solution of $\mathbf{2}$, the silver bromide formed was filtered and the solution left to stand at room temperature, and yellow crystals were obtained.

$\left[\mathrm{Mn}(\mathrm{aaz})(\mathrm{CO})_{3}\right] \mathrm{Br}(\mathbf{1})$

Pale yellow solid, yield 68\%: $70.78 \mathrm{mg} ; 346.97 \mathrm{~g} \mathrm{~mol}^{-1}$; IR (ATR) $v / \mathrm{cm}^{-1} 3335,3192,3097,2024,1879$; UV $\left(\mathrm{H}_{2} \mathrm{O}\right)$ $\lambda_{\max } / \mathrm{nm}$ and its respective $\varepsilon /\left(\mathrm{L} \mathrm{mol}^{-1} \mathrm{~cm}^{-1}\right) 349$ (1317); HRMS (Fourier transform mass spectrometry (FTMS) + pESI) $\mathrm{m} / z$, calcd. for $\mathrm{C}_{9} \mathrm{H}_{15} \mathrm{BrMnN}_{3} \mathrm{O}_{3}[\mathrm{M}]^{+}:$268.0448, found: 268.3712; elemental analysis $\left(\mathrm{C}_{9} \mathrm{H}_{15} \mathrm{BrMnN}_{3} \mathrm{O}_{3}\right)$, found (calculated): C, 30.35 (31.06); H, 4.39 (4.34); N, 11.74 (12.07); ${ }^{1} \mathrm{H}$ NMR (400 MHz, DMSO- $d_{6}$ ) $\delta 1.07$ (s, $\left.3 \mathrm{H}, \mathrm{CH}_{3}\right), 2.30-2.40\left(\mathrm{~m}, 2 \mathrm{H}, \mathrm{CH}_{2}\right), 2.65-2.78\left(\mathrm{~m}, 2 \mathrm{H}, \mathrm{CH}_{2}\right)$, 2.88-2.98 (m, $\left.2 \mathrm{H}, \mathrm{CH}_{2}\right), 3.21\left(\mathrm{~m}, 2 \mathrm{H}, \mathrm{CH}_{2}\right), 4.54(\mathrm{~s}, 2 \mathrm{H}$, $\mathrm{NH}_{2}$ ), 6.24 (s, 2H, NH); ${ }^{13} \mathrm{C}$ NMR (100 MHz, DMSO- $d_{6}$ ) $\delta$ 19.7, 54.1, 58.0, 61.5 .

\section{$\left[\mathrm{Mn}\left(\mathrm{Me}_{2} \mathrm{aaz}\right)(\mathrm{CO})_{3}\right] \mathrm{Br}(\mathbf{2})$}

Pale yellow solid, yield 70\%: $78.98 \mathrm{mg} ; 376.13 \mathrm{~g} \mathrm{~mol}^{-1}$; IR (ATR) $v / \mathrm{cm}^{-1} 3168,2962,2882,2020,1893 ; \mathrm{UV}\left(\mathrm{H}_{2} \mathrm{O}\right)$ $\lambda_{\max } / \mathrm{nm}$ and its respective $\varepsilon /\left(\mathrm{L} \mathrm{mol}^{-1} \mathrm{~cm}^{-1}\right) 354$ (1368); HRMS (FTMS + pESI) $\mathrm{m} / z$, calcd. for $\mathrm{C}_{11} \mathrm{H}_{19} \mathrm{BrMnN}_{3} \mathrm{O}_{3}$ $[\mathrm{M}]^{+}:$296.0817, found: 296.2500; elemental analysis $\left(\mathrm{C}_{11} \mathrm{H}_{19} \mathrm{BrMnN}_{3} \mathrm{O}_{3}\right)$, found (calculated): $\mathrm{C}, 34.79$ (35.13); $\mathrm{H}, 5.27$ (5.09); N, 11.45 (11.17); ${ }^{1} \mathrm{H}$ NMR (400 MHz, DMSO- $\left.d_{6}\right) \delta 1.11\left(\mathrm{~s}, 3 \mathrm{H}, \mathrm{CH}_{3}\right), 2.59-2.72\left(\mathrm{~m}, 2 \mathrm{H}, \mathrm{CH}_{2}\right)$, 2.72-2.86 (m, $\left.2 \mathrm{H}, \mathrm{CH}_{2}\right), 2.96$ (s, $\left.3 \mathrm{H}, \mathrm{CH}_{3}\right), 2.99-3.08$ $\left(\mathrm{m}, 2 \mathrm{H}, \mathrm{CH}_{2}\right), 5.05\left(\mathrm{~s}, 2 \mathrm{H}, \mathrm{NH}_{2}\right) ;{ }^{13} \mathrm{C}$ NMR $(100 \mathrm{MHz}$, DMSO- $\left.d_{6}\right) \delta 20.0,56.5,58.9,64.0,70.6,219.4$.

\section{$\left[\mathrm{Mn}(\operatorname{tacn})(\mathrm{CO})_{3}\right] \mathrm{Br}(\mathbf{3})$}

Pale yellow solid, yield 71\%: $73.9 \mathrm{mg} ; 346.97 \mathrm{~g} \mathrm{~mol}^{-1}$; IR (ATR) $v / \mathrm{cm}^{-1} 3114,2952,2886,2019,1870 ; \mathrm{UV}\left(\mathrm{H}_{2} \mathrm{O}\right)$ $\lambda_{\max } / \mathrm{nm}$ and its respective $\varepsilon /\left(\mathrm{L} \mathrm{mol}^{-1} \mathrm{~cm}^{-1}\right) 344$ (1102); HRMS (FTMS + pESI) $\mathrm{m} / z$, calcd. for $\mathrm{C}_{9} \mathrm{H}_{15} \mathrm{BrMnN}_{3} \mathrm{O}_{3}$ $[\mathrm{M}]^{+}:$268.0448, found: 267.5568; elemental analysis $\left(\mathrm{C}_{9} \mathrm{H}_{15} \mathrm{BrMnN}_{3} \mathrm{O}_{3}\right)$, found (calculated): C, 30.53 (31.06); 
$\mathrm{H}, 4.28$ (4.34); N, 11.58 (12.07); ${ }^{1} \mathrm{H}$ NMR (400 MHz, DMSO- $\left.d_{6}\right) \delta 2.57-2.74\left(\mathrm{~m}, 6 \mathrm{H}, \mathrm{CH}_{2}\right), 2.81-2.98(\mathrm{~m}, 6 \mathrm{H}$, $\left.\mathrm{CH}_{2}\right), 6.71(\mathrm{~s}, 3 \mathrm{H}, \mathrm{NH}) ;{ }^{13} \mathrm{C}$ NMR (100 MHz, DMSO- $\left.d_{6}\right)$ $\delta$ 49.7, 220.9 .

\section{Results and Discussion}

\section{Solid state characterization}

In order to avoid oxidation of the $\mathrm{Mn}^{\mathrm{I}}$ ion we performed the syntheses with extended reaction times in dry, degassed solvent, as described in the Experimental section. With this approach and after recrystallization in adequate solvent, single crystals, suitable for X-ray analysis, were obtained for all compounds.

The molecular arrangements for compounds 1, 2 and 3 are shown in Figure 2. As expected, all structures have distorted octahedral coordination geometry, with the nitrogen-rich ligands presenting a facial coordination mode. Compound 1 crystallizes in a monoclinic system and $P 2_{1} / \mathrm{c}$ spatial group whereas compounds $\mathbf{2}$ and $\mathbf{3}$ crystallize in the orthorhombic space groups Pna21 and Pbca, respectively. The bond angles show larger distortions for $\mathbf{1}$ and $\mathbf{2}$, as a direct result of the aaz and $\mathrm{Me}_{2}$ aaz ligands. These ligands have more conformational freedom when compared to the tacn used for $\mathbf{3}$, resulting in more differentiated bond angles (Table 1). The Mn1-C bonds are shorter than $\mathrm{Mn} 1-\mathrm{N}$ bonds due the strong $\pi$-back-bonding effect between these atoms which increases the distortion in the octahedral geometry. In the structures of compounds $\mathbf{1}$ and $\mathbf{2}$ the Mn1-N1 bond distances (2.068(3) $\AA$ for $\mathbf{1}$ and 2.046(4) $\AA$ for 2) are shorter than the Mn1-N2 (2.097(3) $\AA$ for $\mathbf{1}$ and 2.110(6) $\AA$ for 2) and Mn1-N3 (2.098(3) $\AA$ for 1 and 2.109(5) $\AA$ for 2) bonds thereto. This occurs because the amine nitrogen N1 is positioned outside the chelate ring of these ligands which gives it greater conformational freedom and interaction with the metal center of $\mathrm{Mn} 1$. Consequently, the $\mathrm{Mn} 1-\mathrm{C} 1$ binding lengths for these two compounds, 1.804(4) $\AA$ for $\mathbf{1}$ and 1.793(6) $\AA$ for 2 are slightly shorter than Mn1-C2 (1.809(4) for 1 and 1.801(7) $\AA$ for 2) and Mn1-C3 (1.806(4) $\AA$ for 1 and 1.811(7) $\AA$ for 2) due to the trans-influence. As the $\mathrm{N} 1$ atom is closer to the metal center it increases the electron density on it resulting in a higher $\pi$-back-bonding between the $\mathrm{Mn} 1-\mathrm{C} 1$ atoms in comparison to $\mathrm{Mn} 1-\mathrm{C} 2$ and $\mathrm{Mn} 1-\mathrm{C} 3$ atoms for $\mathbf{1}$ and $\mathbf{2}$. On the other hand, for compound $\mathbf{3}$ all Mn1-N bonding distances are very similar since the tacn is a symmetrical macrocyclic ligand. Furthermore, compounds 1-3 present bond angles and bond lengths which are comparable to $\mathrm{Mn}^{\mathrm{I}}$ triscarbonyl compounds with nitrogen chelating ligands already reported in the literature, for example $\left[\mathrm{Mn}(\mathrm{CO})_{3}\left(k^{3} \text {-tpa }\right)\right]^{+} .31$
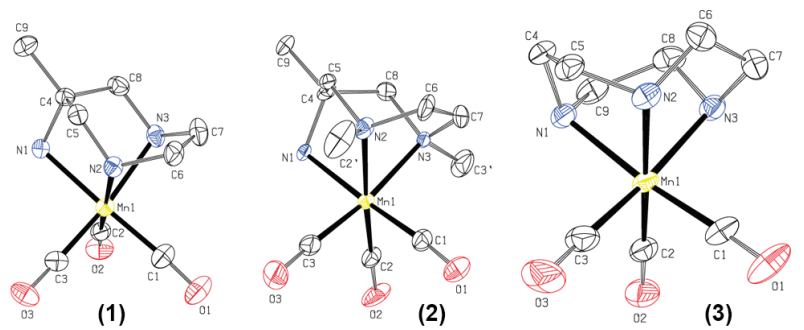

Figure 2. Molecular structure of cation complexes 1-3 from left to right, hydrogen and counter-ions are omitted for clarity. Thermal ellipsoids are shown at $50 \%$ probability level.

Table 1. Selected bond lengths and angles of 1-3

\begin{tabular}{lcccc}
\hline & & $\mathbf{1}$ & $\mathbf{2}$ & $\mathbf{3}$ \\
\hline & Mn1-C1 & $1.804(4)$ & $1.793(6)$ & $1.809(3)$ \\
& Mn1-C2 & $1.809(4)$ & $1.801(7)$ & $1.814(3)$ \\
Bond & Mn1-C3 & $1.806(4)$ & $1.811(7)$ & $1.802(3)$ \\
length / A & Mn1-N1 & $2.068(3)$ & $2.046(4)$ & $2.074(2)$ \\
& Mn1-N2 & $2.097(3)$ & $2.110(6)$ & $2.069(2)$ \\
& Mn1-N3 & $2.098(3)$ & $2.109(5)$ & $2.071(2)$ \\
\hline & $\mathrm{C} 1-M n 1-\mathrm{C} 2$ & $86.22(16)$ & $88.2(3)$ & $90.02(12)$ \\
Bond & $\mathrm{C} 1-\mathrm{Mn} 1-\mathrm{C} 3$ & $90.11(18)$ & $89.8(3)$ & $88.95(14)$ \\
angle / & $\mathrm{C} 2-\mathrm{Mn} 1-\mathrm{C} 3$ & $92.09(15)$ & $89.3(4)$ & $90.11(13)$ \\
degree & $\mathrm{N} 1-\mathrm{Mn} 1-\mathrm{N} 2$ & $81.15(10)$ & $82.3(2)$ & $81.19(8)$ \\
& $\mathrm{N} 1-\mathrm{Mn} 1-\mathrm{N} 3$ & $82.33(11)$ & $81.93(19)$ & $81.12(8)$ \\
& $\mathrm{N} 2-\mathrm{Mn} 1-\mathrm{N} 3$ & $74.58(11)$ & $76.6(2)$ & $80.88(8)$ \\
\hline
\end{tabular}

The infrared spectra of the ligands and the complexes show the coordination between the metal ions and the ligands through the amine nitrogen. The bands characteristic of the $\mathrm{NH}$ and $\mathrm{NH}_{2}$ groups appear in the region of 3300 to $3400 \mathrm{~cm}^{-1}$ for the free ligands, whereas for compounds $\mathbf{1 - 3}$ this band is shifted to the lower energy region, indicating coordination of the ligand to the metal ion through the nitrogen.

The infrared results also corroborate the facial ligand arrangement, since their symmetry resembles that of a $C_{3} v$ point group, displaying two intense vibrational stretching bands, at around 2100 and $1800 \mathrm{~cm}^{-1}$. The former is associated with the symmetrical $\mathrm{CO}$ stretching and the latter is attributed to the two degenerate asymmetrical $\mathrm{CO}$ stretching bands, which are directly influenced by the symmetry of the ligands. As an example, compound $\mathbf{3}$, which shows the most symmetry, displays high degeneracy of the asymmetrical band. In contrast, upon increasing the asymmetry from $\mathbf{1}$ to $\mathbf{2}$ the asymmetrical bands tend to split, forming three CO stretching bands (Figures S1-S3, Supplementary Information (SI) section).

Identification of the initial species in solution

Besides the solid-state characterization, the stability of the title compounds was assessed in water and acetonitrile 
solutions. All compounds have high stability in both media in the dark, showing only slight changes of the absorption spectra over a period of $14 \mathrm{~h}$ (Figure S4, SI section). Complexes $\mathbf{1}$ and $\mathbf{2}$ showed less than 3\% of spectral variation while complex $\mathbf{3}$ remained practically unchanged. Furthermore, the ESI-MS analysis conducted in acetonitrile confirms the stability of 1-3 in the dark, since the compounds do not exhibit $\mathrm{CO}$ release during the analysis, where the molecular ion is the base peak (Figures S5-S7, SI section).

The absorption spectra of $\mathbf{1}, \mathbf{2}$ and $\mathbf{3}$ in water show intense bands at 350,355 and $346 \mathrm{~nm}$, respectively, and a minor shoulder at around $268 \mathrm{~nm}$ (Figure 3a), which
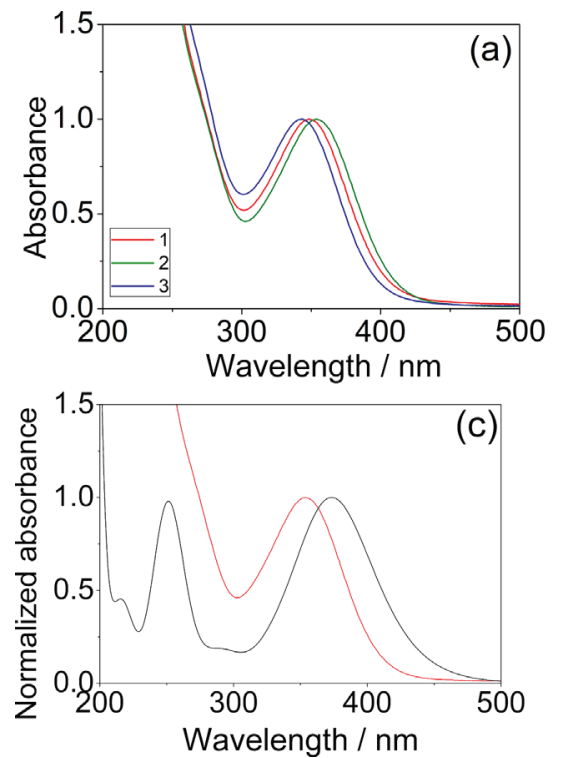

are in agreement with the theoretical values. The analysis of the calculated excitations indicates that the lower energy band has two major transitions (Figure 4) and the higher energy band has three major transitions, both associated with excitations of the $\mathrm{Mn}^{\mathrm{I}} d$ to the $\mathrm{p} \pi^{*}$ nitrogen orbitals. The superposition of the theoretical spectra with the experimental results showed good agreement (Figures 3b-3d).

TD-DFT calculations with the conductor-like polarizable continuum model (CPCM) solvation model on the optimized ground states of $\mathbf{1 - 3}$ revealed that the orbitals of both absorptions have major contributions from the highest occupied molecular orbitals (HOMOs), which
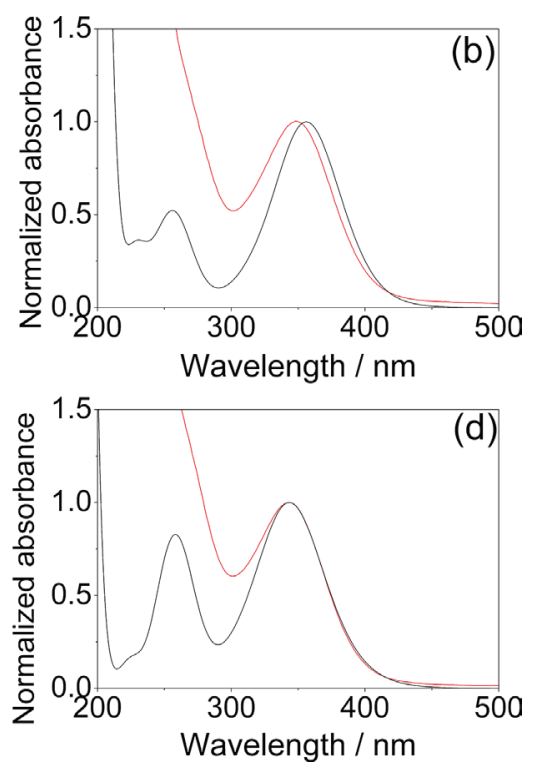

Figure 3. (a) Absorption spectra of 1-3 in aqueous solution; (b, c, d) superposed absorption spectra (red dashed line) and theoretical values (black line) for 1-3, respectively, obtained from plotting a Gaussian distribution with $\sigma=0.3 \mathrm{eV}$ over the twenty most prominent calculated excitations.

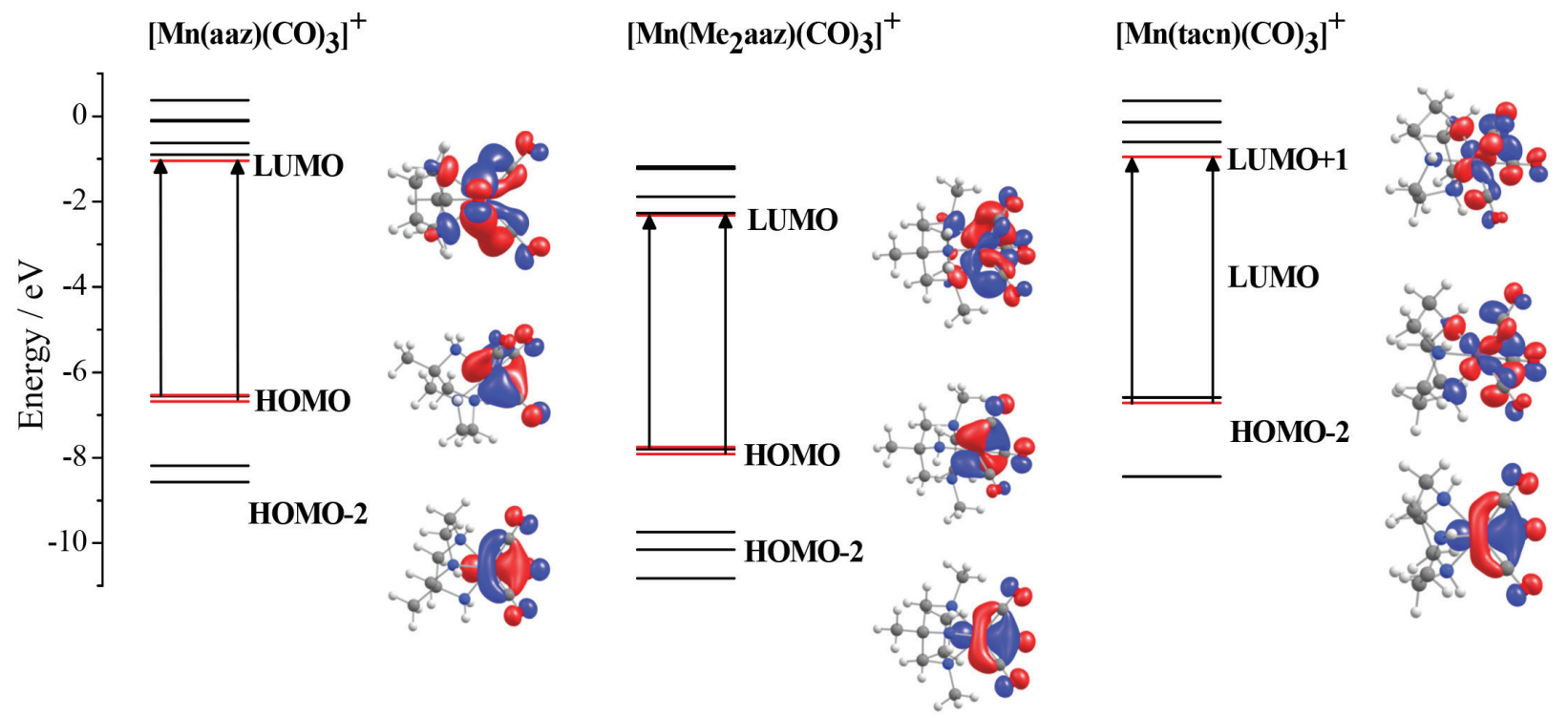

Figure 4. The first six molecular orbitals (HOMO and LUMO) calculated for 1-3 ions. The most prominent MOs involved in the transitions under the lower energy band are highlighted. 
are mostly composed of the $\mathrm{Mn}^{\mathrm{I}} d$ orbitals and oxygen $p$ orbitals, whereas the lowest unoccupied molecular orbital (LUMOs), which have a higher degree of delocalization, are composed of $\pi^{*} \mathrm{Mn}-\mathrm{CO}$ and $\mathrm{p} \pi^{*}$ nitrogen orbitals.

The HOMO energy values show the following trend: $\mathbf{1}>\mathbf{3}>\mathbf{2}$, which is in agreement with the increase in the number of carbons attached to nitrogen atoms, directly influencing the $\sigma$-donating capabilities of the tridentate ligands. However, the LUMO energies value do not follow the same trend, showing a shift in the stabilization on comparing compounds $\mathbf{1}$ and $\mathbf{3}$, resulting in band gap values of 5.49, 5.43 and $5.64 \mathrm{eV}$ for $\mathbf{1}, \mathbf{2}$ and $\mathbf{3}$, respectively. Another key feature that appears when analyzing the calculated molecular orbitals (MOs) is that the increased symmetry from the tacn ligand imposes a higher degeneracy of the bonding MOs.

Correlations between the electronic spectra and the redox potentials for 1-3 were observed. The cyclic voltammograms for the three compounds in acetonitrile show two irreversible processes: the first at 624, 621 and $630 \mathrm{mV}$ (vs. normal hydrogen electrode (NHE)) and the second at 1266, 1267 and $1265 \mathrm{mV}$ ( $v s . \mathrm{NHE}$ ), for $\mathbf{1}, 2$ and $\mathbf{3}$, respectively. The first and second processes are attributed to the redox pairs $\mathrm{Mn}^{\mathrm{I}} \rightleftharpoons \mathrm{Mn}^{\mathrm{II}}$ and $\mathrm{Mn}^{\mathrm{II}} \rightleftharpoons \mathrm{Mn}^{\mathrm{III}}$, respectively (Figures S8-S10, SI section). The high oxidation potentials of the manganese centers are due to the presence of the strong $\pi$ acceptor $\mathrm{CO}$ groups, which decreases the electronic density on the metal, hindering the stabilization of higher oxidation states.

On changing the oxidation state of the manganese centers in the molecules there is a tendency for the $\mathrm{CO}$ from the first coordination to be replaced with solvent molecules, causing a strong change in the conformation of the compounds and influencing the reversibility of the processes. A lower intensity signal in the voltammograms for each compound can be observed close to the $\mathrm{Mn}^{\mathrm{II}} \rightleftharpoons \mathrm{Mn}^{\mathrm{III}}$ oxidation potentials. This can be attributed to conformational changes due to the $\mathrm{CO}$ release during the oxidation process, which could either be attributed to the exchange of ligands or changes in the spin multiplicity. Unfortunately, the redox potential of this type of compound has not been widely studied, however, these properties are discussed in higher depth in the section related to the mechanistic processes involved in the photorelease of $\mathrm{CO}$.

Considering the fact that the compounds 1-3 are diamagnetic, it was possible to perform NMR experiments in solution. In the ${ }^{1} \mathrm{H}$ NMR analysis results (Figure S11, SI section), compounds $\mathbf{1}$ and $\mathbf{2}$ show similar spectral profiles, where all of the methyl and methylene groups can be clearly observed. For compound $\mathbf{3}$, the spectrum obtained was quite different, showing only a methylene group in its structure and thus revealing a more symmetrical structure. Some of the resonance lines are broader and their magnetic splitting is altered due to the structural rigidity of the ligand imposed by the complexation process. Finally, primary ( 4.54 and $5.05 \mathrm{ppm}$ for $\mathbf{1}$ and $\mathbf{2}$, respectively) and secondary (6.24 and $6.71 \mathrm{ppm}$ for $\mathbf{1}$ and $\mathbf{3}$, respectively) amine hydrogen atoms were easily detected.

The ${ }^{13} \mathrm{C}$ NMR spectra (Figure S12, SI section) of compounds $\mathbf{1}$ and $\mathbf{2}$ show similar features, except for the resonance line at $70.6 \mathrm{ppm}$ in the spectrum of $\mathbf{2}$, corresponding to the $N$-methyl group, which is absent from the spectrum of $\mathbf{1}$. Once again, $\mathbf{3}$ reveals only one signal at $49.7 \mathrm{ppm}$, confirming its symmetrical ligand characteristic. All compounds show signals at around $220 \mathrm{ppm}$, attributed to the carbonyl groups attached to the manganese center. These ${ }^{13} \mathrm{C}$ chemical shifts for the $\mathrm{CO}$ groups are in agreement with results for similar compounds described previously. ${ }^{36}$

\section{Photoactivated CO-release properties}

In order to understand the photorelease behavior of the compounds 1-3 different wavelength light sources were tested, and the value of $385 \mathrm{~nm}$ was chosen because it leads to the most efficient photorelease and is very close to the calculated maximum wavelength for these compounds.

The changes in the $\mathrm{CO}$ stretching bands of compounds 1-3 upon exposure to $\lambda_{385}$ was monitored by IR spectroscopy (Figure 5). As expected, after light exposure, the $\mathrm{CO}$ stretching bands located between 2050 to $1900 \mathrm{~cm}^{-1}$ showed a steady decrease in intensity, until virtually disappearing after $1 \mathrm{~h}$, indicating complete release from 1-3, in agreement with the hemoglobin assay.

Besides noting the absence of the $\mathrm{CO}$ stretching bands after light exposure, the appearance of new lower intensity bands at lower frequencies was observed after $6 \mathrm{~min}$ of irradiation. These new bands are associated with the formation of biscarbonyl intermediates, which show CO stretching bands between $1950-1800 \mathrm{~cm}^{-1}$, as also noted by Kurz's research group. ${ }^{30,31}$ This is in agreement with the $\mathrm{CO}$ stretching frequencies calculated for the intermediates, using DFT and the CPCM solvation model, exchanging the carbonyl ligand for an acetonitrile molecule (Table S1, SI section). The calculations indicate that all intermediates show one symmetric CO stretching band at around 1990 to $1960 \mathrm{~cm}^{-1}$, which should be superposed by the asymmetric bands of the initial compounds, but this could not be observed during the photolysis experiments. The second CO stretching band at around 1900 to $1850 \mathrm{~cm}^{-1}$, which appears in the photolysis experiments, is attributed to the asymmetric mode and confirmed by the theoretical values. 

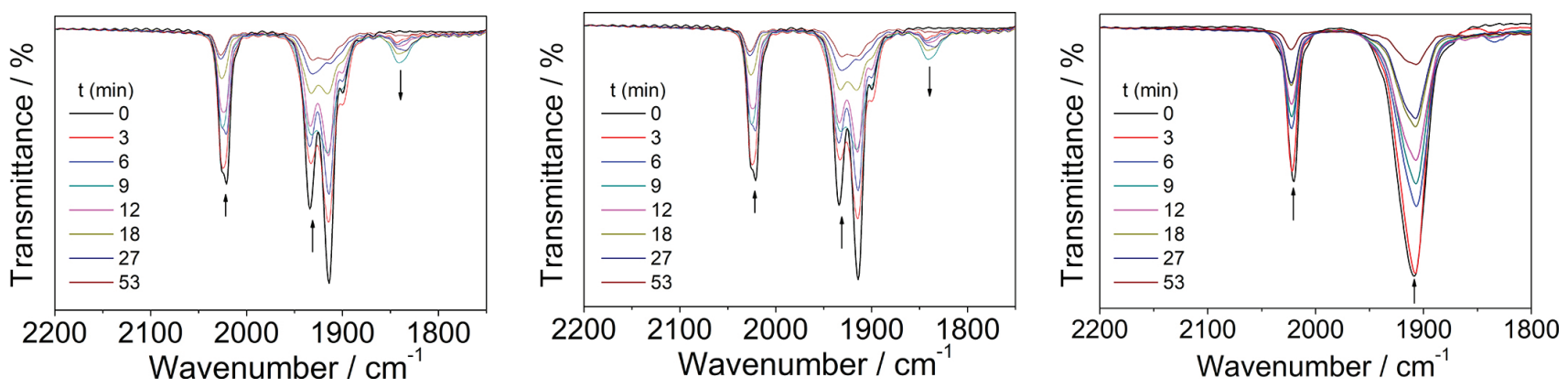

Figure 5. Changes in the infrared spectra (KBr) of $\mathbf{1}$ (left), $\mathbf{2}$ (middle) and $\mathbf{3}$ (right) caused by CO released during $\lambda_{385}$ excitation, in acetonitrile solution.

The presence of these new bands is more evident for $\mathbf{1}$ and 2, showing that for these compounds there is a buildup of the intermediate with two CO units. In contrast compound $\mathbf{3}$ does not show an increase in the intermediate concentration over time. This indicates that, after the excitation, the mechanisms involved in the release of carbon monoxide from compounds $\mathbf{1}$ and $\mathbf{2}$ are similar, while $\mathbf{3}$ readily loses the two remaining carbonyls after the first dissociation. Based on a comparison of the theoretical and experimental frequencies we propose that the intermediates biscarbonyl $\mathbf{1}$ and $\mathbf{2}$ are formed by the release of the carbonyl group trans to the $\mathrm{NH}_{2}$ group of the aaz and $\mathrm{Me}_{2}$ aaz ligands.

The stability of the intermediates formed during the photodecomposition of $\mathbf{1}$ and $\mathbf{2}$ were also monitored in the absence of light, and in both cases the intermediates show only minor modifications of the CO stretching bands.

Analysis of the photoproducts by square wave voltammetry (Figure S13, SI section) demonstrated that after 6 min of light exposure, $\mathbf{1}$ and $\mathbf{2}$ show a new process at 0.383 and $0.493 \mathrm{~V} v s$. NHE, respectively, attributed to the biscarbonyl intermediate, which does not change in the absence of light for $30 \mathrm{~min}$. Overall, for both compounds, the manganese oxidation process continues for some time after the formation of the intermediates, with the modification of the potentials. However, when re-exposing the solutions to light, the initial species and the intermediates tend to lose the remainder of the $\mathrm{CO}$ and oxidize, lowering the intensity of the processes. A similar behavior was observed by Kurz and co-workers ${ }^{31}$ for $\left[\mathrm{Mn}(\mathrm{CO})_{3}(\mathrm{tpm})\right]\left[\mathrm{PF}_{6}\right]$. In this case, during cyclic voltammetry, the process occurred after $30 \mathrm{~min}$ of light $\left(\lambda_{365} \mathrm{~nm}\right)$ exposure, with the appearance of a signal at $0.050 \mathrm{~V} v s$. $\mathrm{Fc} / \mathrm{Fc}^{+}$, attributed to oxidation of the intermediate $\left[\mathrm{Mn}(\mathrm{CO})_{2}(\mathrm{tpm})\left(\mathrm{CH}_{3} \mathrm{CN}\right)\right]^{+}$. This low oxidation potential of the biscarbonyl intermediate is due to the presence of only two strong $\pi$-accepting $\mathrm{CO}$ ligands, which increases the electron density on the $\mathrm{Mn}^{\mathrm{II}}$ metal center, facilitating its oxidation. ${ }^{31}$

In contrast, when 3 (Figure S13, right, SI section) was exposed to light for $6 \mathrm{~min}$, two processes appear: one at $0.423 \mathrm{~V}$ and the other at $0.655 \mathrm{~V} v s$. NHE, both probably associated with the biscarbonyl species. However, in the absence of light, after $30 \mathrm{~min}$, the stability of the intermediate formed decreases, probably due to autooxidation of the species formed at $0.332 \mathrm{~V}$, which readily loses the other two carbonyls after the first dissociation.

In addition, the ESI-MS of the photoproducts (Figure 6) revealed that the compounds release only one $\mathrm{CO}$ molecule after 6 min of exposure to $\lambda_{385}$, exchanging the carbonyl group for a solvent molecule and retaining the $\mathrm{Mn}^{\mathrm{I}}$ center, displaying peaks at 281.08 for $\mathbf{1}$ and $\mathbf{3}$ and 309.27 for $\mathbf{2}$. This is coherent with the mechanism proposed by Kurz's research group. ${ }^{30,31}$ Unfortunately, during the analysis no other species resulting from the oxidation of the metal center were detected in appreciable amounts, even with longer exposures.

In order to determine the rates of the $\mathrm{CO}$ photorelease, the decomposition of 1-3 upon light irradiation were monitored
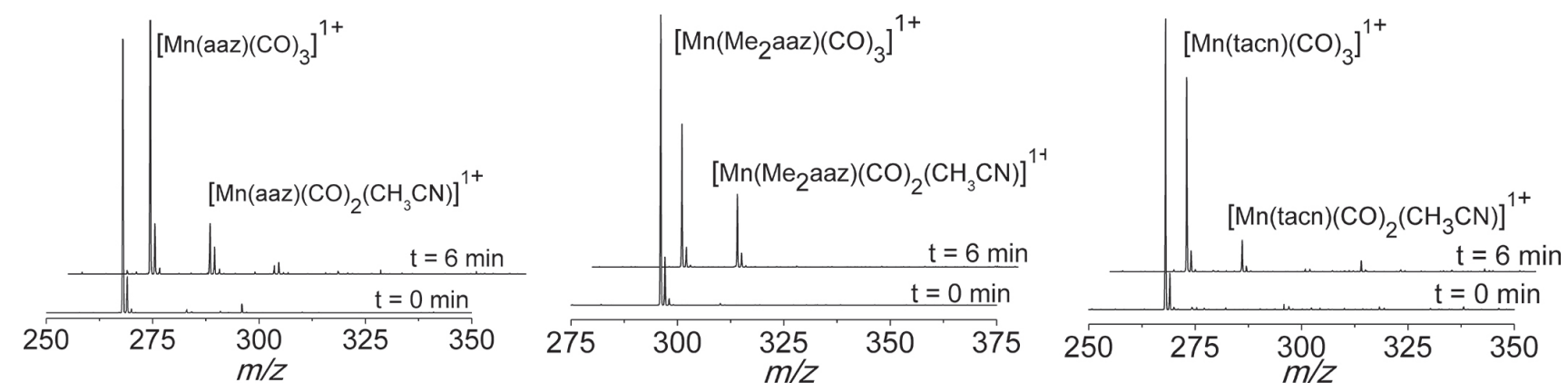

Figure 6. ESI-MS of 1-3 (from left to right) without irradiation and after 6 min of irradiation with $\lambda_{385}$. 
spectrophotometrically over time in both optimum wavelengths $\left(\lambda_{385}=385 \pm 10 \mathrm{~nm}\right.$ and $\left.\lambda_{410}=410 \pm 5 \mathrm{~nm}\right)$, in order to infer whether there is a significant change in the photorelease rates.

Since, during the $\mathrm{CO}$ release experiment, 1-3 form a biscarbonyl species after about $6 \mathrm{~min}$, the decay rates of the initial species was considered up to this time, disregarding the influence of the intermediate on the calculated rate. Moreover, the quantum yield was also determined using the ferrioxalate actinometry assay ${ }^{19}$ to determine the photon flux of the light sources used, using the same time interval.

The title compounds only showed some degree of decomposition when exposed to UV-A/violet light, with $\lambda_{385}$ (calculated photon flux $=1.13 \times 10^{-8}$ Einstein s$^{-1}$ ) and $\lambda_{410}$ (calculated photon flux $=1.03 \times 10^{-8}$ Einstein $\mathrm{s}^{-1}$ ), respectively. At these wavelengths a decrease in the band centered at around $350 \mathrm{~nm}$ was observed until their stabilization around 16 and $36 \min$ for $\lambda_{385}$ and $\lambda_{410}$, respectively, when the solutions had a clear brown/yellow color. Figure 7 illustrates this behavior for complex $\mathbf{2}$, while spectral data for complexes $\mathbf{1}$ and $\mathbf{3}$ are provided in Figures S14-S17 (SI section).

The results show that the decay rate and the quantum yields are directly proportional and that the $\mathrm{CO}$ release processes are faster during exposure to $\lambda_{385}$, in which all compounds showed higher quantum yield values compared to those found for $\lambda_{410}$ exposure. These data are consistent with the absorption spectra and the calculated electronic transitions, which showed a strong absorption band around $350 \mathrm{~nm}$, where the first major electronic transitions are observed, which are much closer to the UV-A wavelength used. During exposure to $\lambda_{385}$ light, compound 2 was more active showing both a higher decay rate and quantum yield value, while the quantum yields for $\mathbf{1}$ and $\mathbf{3}$ were very similar (Table 2). This higher activity of $\mathbf{2}$ can be explained by the presence of two methyl groups, which increases the $\sigma$-donating capabilities of the ligand, similarly to the use of $\mathrm{Br}$ and $\mathrm{PPh}_{3}$ coligands in the first coordination sphere, ${ }^{37}$ increasing the maximum wavelength of the first major electronic transitions for compound $\mathbf{2}$, which is then closer to the incident wavelength. On increasing the incident light wavelength to $\lambda_{410}$, all compounds showed incomplete $\mathrm{CO}$ release and, therefore, the decomposition rates are slower than with $\lambda_{385}$ and very similar.

The CO release was also studied using hemoglobin as a $\mathrm{CO}$ detector. ${ }^{35}$ To eliminate any doubt regarding the interference of sodium dithionite in the $\mathrm{CO}$ release activity, the spectra were obtained for 1-3 without light irradiation and did not reveal any change in the $\mathrm{Q}$ bands of hemoglobin. The solutions were then exposed to the $\lambda_{385}$ wavelength at fixed time intervals and the formation of $\mathrm{HbCO}$ was monitored by the decrease in the $\mathrm{Hb} 557 \mathrm{~nm}$ band and the appearance of two new bands at 538 and $567 \mathrm{~nm}$ associated with the conversion from $\mathrm{Hb}$ to $\mathrm{HbCO}$ (Figures S18-S20, SI section).

Considering these results, it is plausible to propose that the excitation of compounds $\mathbf{1}$ and $\mathbf{2}$ in $\lambda_{385}$ wavelength releases one carbon monoxide molecule, forming a stable intermediate that does not undergo spontaneous oxidation, retaining the $\mathrm{Mn}^{\mathrm{II}}$ center, and further $\mathrm{CO}$ release is only accomplished by light exposure. On the other hand, upon release of the first carbon monoxide molecule from compound 3 , the intermediate is rapidly oxidized, releasing all three $\mathrm{CO}$ units consecutively.
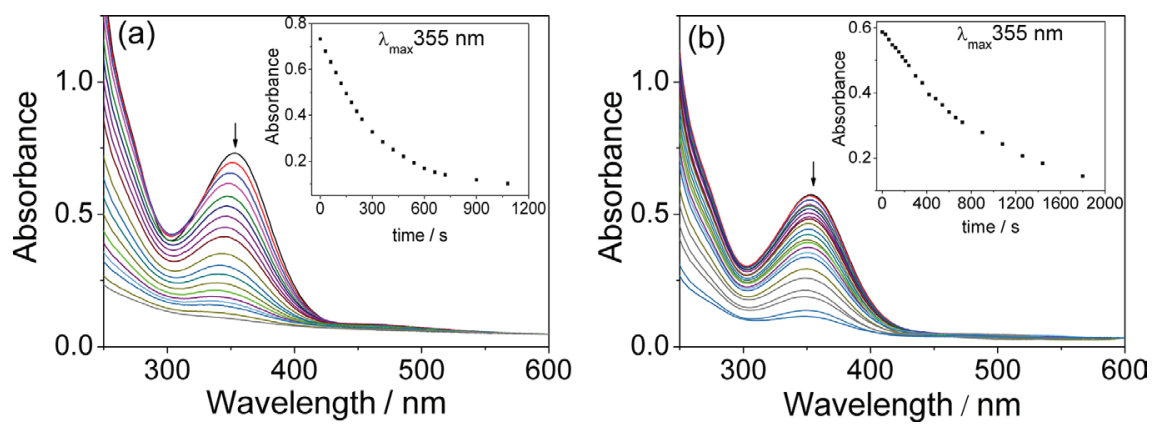

Figure 7. Changes in the UV-Vis spectra of a $1.0 \times 10^{-3} \mathrm{~mol} \mathrm{~L}^{-1}$ aqueous solution of compound 2 during the course of irradiation at (a) $\lambda_{385}$ and (b) $\lambda_{410}$.

Table 2. Quantum yield of CO release for compounds $\mathbf{1 - 3}$ under irradiation at $\lambda_{385}=385 \pm 10 \mathrm{~nm}$ and $\lambda_{410}=410 \pm 5 \mathrm{~nm}$

\begin{tabular}{lccc}
\hline Compound & Quantum yield & Rate $\lambda_{385} \times 10^{-7} /\left(\mathrm{mol} \mathrm{L}^{-1} \mathrm{~s}^{-1}\right)$ & \multicolumn{2}{c}{ Quantum yield } \\
$\lambda_{385}$ & $6.65 \pm 0.61$ & $0.044 \pm 0.003$ \\
$\mathbf{1}$ & $0.058 \pm 0.008$ & $9.10 \pm 0.21$ & $0.033 \pm 0.003$ \\
$\mathbf{3}$ & $0.081 \pm 0.002$ & $5.48 \pm 0.23$ & $3.17 \pm 0.48$ \\
\hline
\end{tabular}


These proposed mechanisms are also in agreement with the quantum yield of $\mathrm{CO}$ release: quantum yield in $\lambda_{385} 2>\mathbf{1}>3$. In the case of compound 2 , the $\sigma$-donating capabilities of the methyl groups incorporated into the ligand seem to have a greater influence, whereas $\mathbf{1}$ and $\mathbf{3}$, even though the excitation behaviors are similar, seem to be more influenced by the higher degree of oxidation after the release of the first $\mathrm{CO}$. These results are consistent with those published by Kurz and co-workers. ${ }^{30,31}$

When the photo-triggered $\mathrm{CO}$ release from the compounds 1-3 was studied via ${ }^{1} \mathrm{H}$ NMR, interesting features could be observed. The magnitudes of the quantum yield of CO release found by electronic spectroscopy (quantum yield in $\lambda_{385} \mathbf{2}>\mathbf{1}>\mathbf{3}$ ) are reflected in the NMR spectral changes over time. Figure 8 illustrates this behavior for complex $\mathbf{2}$ while the results for complexes $\mathbf{1}$ and $\mathbf{3}$ are provided in the Supplementary Information (Figures S21 and S22, respectively).
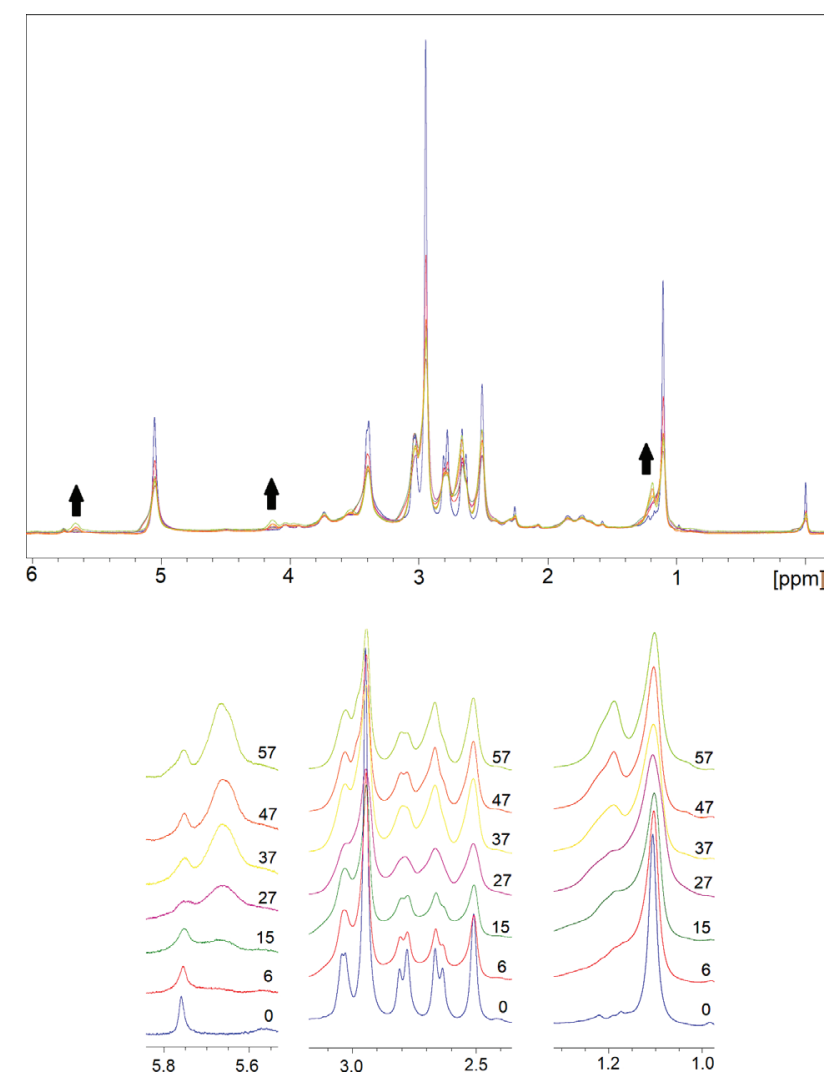

Figure 8. ${ }^{1} \mathrm{H}$ NMR spectral modifications for $2\left(400 \mathrm{MHz}, \mathrm{DMSO}-d_{6}\right)$ upon irradiation with $\lambda_{385}$ light. Full spectrum (top) and selected expansions (bottom). Time intervals: 0, 6, 16, 27, 37, 47, and $57 \mathrm{~min}$.

Qualitatively, for all compounds, several new signals appeared on the ${ }^{1} \mathrm{H}$ spectra between 4.0 and $6.0 \mathrm{ppm}$ after around $50 \mathrm{~min}$ of light exposure. This result could be related to the carbonyl dissociation with a concomitant solvent coordination (DMSO- $d_{6}$ ), generating new species in solution. Considering the proximity of the nitrogenattached protons $(\mathrm{NH})$ of primary and secondary amines to the metal center, they can experience major shielding effects caused by the exchange of the exogenous ligands. Thus, more NH bonds are present in the compounds, as more new resonance lines appeared, over time. Considering the region between 1.0 and $4.0 \mathrm{ppm}$ (methyl and methylene groups), all compounds showed smaller modifications, since these groups are distant from the manganese center. Interestingly, for $\mathbf{1}$ and $\mathbf{2}$, the singlet at around $1.0 \mathrm{ppm}\left(\mathrm{CH}_{3}\right.$ group attached to the quaternary carbon of aaz and aaz- $-\mathrm{Me}_{2}$ ligands, respectively) presented the same effect observed for the amine protons mentioned above. In the case of compound $\mathbf{1}$, two new singlets were detected, which may indicate new species generated in solution (Figure S21, SI section). The same trend can be observed for 2 (Figure 8); however, it is less pronounced since the carbonyl release is faster compared with $\mathbf{1}$ and thus less detectable.

On the ${ }^{13} \mathrm{C}$ spectra for $\mathbf{1 - 3}$ (Figures S23-S25, SI section), very elucidative features could be noted. For all compounds, when the spectra were taken before light exposure, a signal at around $220 \mathrm{ppm}$ was detected, which relates to the manganese-bonded carbonyl group. After light exposure (around $50 \mathrm{~min}$ ) a new resonance line is detected for all compounds between 180 and $190 \mathrm{ppm}$, attributed to the free carbonyl group in solution. This feature is in agreement with results obtained using other techniques, such as electrochemistry and mass spectrometry. Finally, for all resonance lines ascribed to the macrocyclic ligands (between 20 and $70 \mathrm{ppm}$ ), after light exposure new signals appeared around each line, which confirms the presence of different species in solution.

Based on these results a CO-release mechanism can be proposed for compounds 1-3 (Figure 9), which consists of two steps. After approximately $6 \mathrm{~min}$ of light exposure, all compounds release one equivalent of $\mathrm{CO}$ resulting in a biscarbonyl species with a solvent molecule replacing the CO released. This is confirmed by the ESI-MS, IR, and NMR spectroscopy results. At this point the compounds could be separated into two groups. For the first group, containing compounds $\mathbf{1}$ and $\mathbf{2}$, we propose that after the release of the first $\mathrm{CO}$ the two remaining $\mathrm{CO}$ molecules are released after longer exposure to light with subsequent oxidation of the metal center (from $\mathrm{Mn}^{\mathrm{I}}$ to $\mathrm{Mn}^{\mathrm{II}}$ ). This is corroborated by the IR spectra, which show that the new signals attributed to the biscarbonyl intermediate disappear after longer exposure to light (Figure 5). In addition, the signals relating to $\mathrm{CO}$ stretching in the starting compounds disappear completely, verifying the release of all CO molecules. For the second group (compound $\mathbf{3}$ ), we propose that after the first $6 \mathrm{~min}$ under light exposure simultaneously 

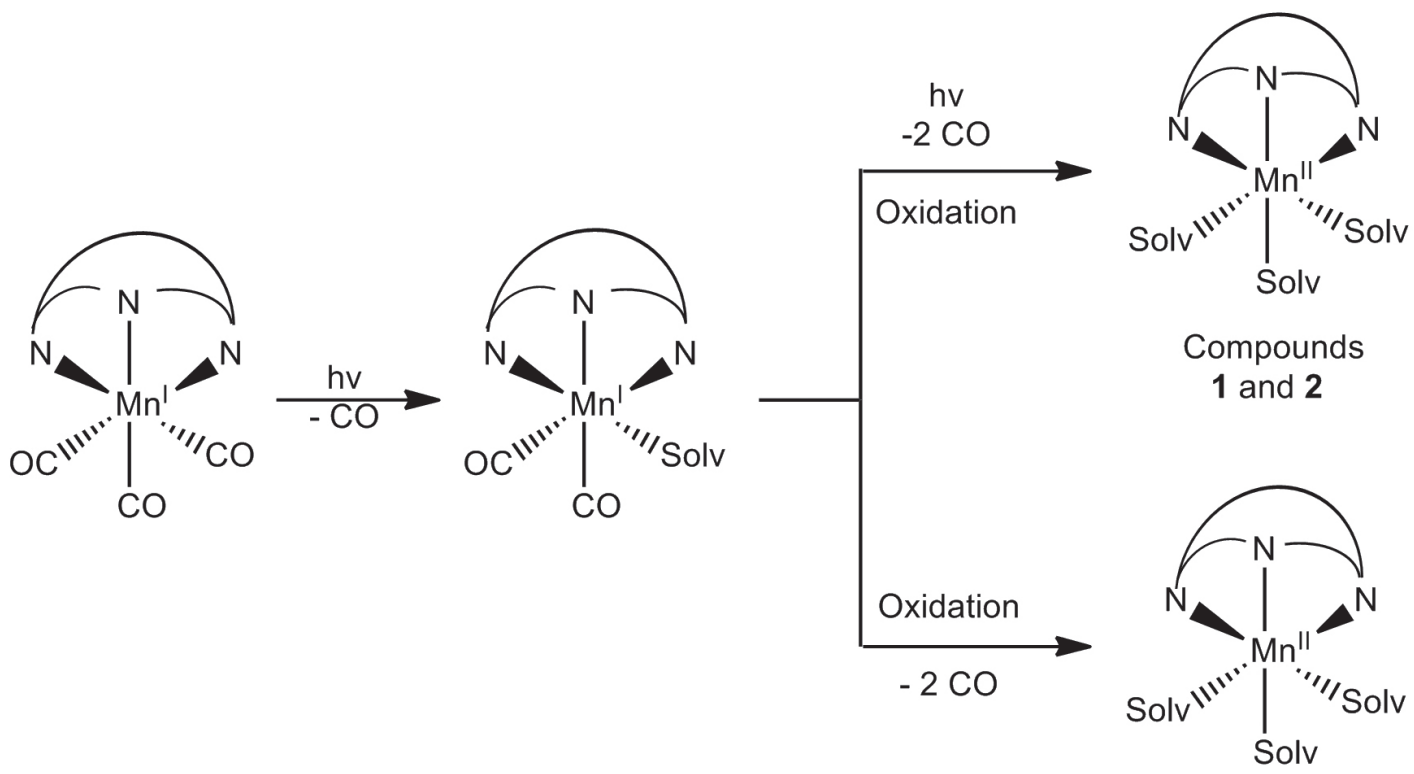

Compound 3

Figure 9. Proposed schematic representation of the CO release for 1-3.

occur the oxidation of the metal center $\left(\mathrm{Mn}^{\mathrm{I}} / \mathrm{Mn}^{\mathrm{II}}\right)$ and the release of the two remaining $\mathrm{CO}$ molecules. This is corroborated by the IR spectrum for this compound, which does not show the appearance of a new signal relating to the biscarbonyl intermediate. However, this new signal does appear on the mass spectrum. This suggests that, for compound $\mathbf{3}$, this intermediate is unstable leading to rapid oxidation of the metal center with the subsequent release of the other two $\mathrm{CO}$ molecules after a longer exposure to light, which is evidenced by the disappearance of the bands associated with the CO stretching in the IR spectrum. Regarding compounds $\mathbf{1}$ and $\mathbf{2}$, the oxidation of the metal center can be confirmed by the ${ }^{1} \mathrm{H}$ NMR results, where the resonance lines become broad, indicating the paramagnetism of the $\mathrm{Mn}^{\mathrm{II}}$ metal center. Some researchers suggest the dimerization of the metal centers after the release of the $\mathrm{CO}$ molecules, ${ }^{30,31}$ but our results did not confirm this.

\section{Conclusions}

Three water-soluble $\mathrm{Mn}^{\mathrm{I}}$ tricarbonyl compounds with the cyclic ligands aaz, $\mathrm{Me}_{2} \mathrm{aaz}$ and tacn were synthesized. The compounds released $\mathrm{CO}$ molecules when exposed to light $\left(\lambda_{385}\right.$ and $\left.\lambda_{410}\right)$, thus acting as photoCORMs. Excitation at a wavelength of $\lambda_{385}$ caused the fastest CO release for all compounds and $\mathbf{2}$ had the faster $\mathrm{CO}$ release under this condition. Using the combined techniques of IR, UV-Vis and NMR spectroscopies, along with ESI-MS and electrochemistry, it was possible to identify the formation of a biscarbonyl intermediate for all compounds during the photo-release process. On applying the hemoglobin assay for 95 min using light at $\lambda_{385}$, the compounds showed CO release and we did not observe an influence of sodium dithionite in this process. The $\mathrm{CO}$ release appears to occur in two steps, as shown in Figure 9 with compounds $\mathbf{1}$ and $\mathbf{2}$ exhibiting a slightly different mechanism compared with compound 3 .

\section{Supplementary Information}

Crystallographic data (excluding structure factors) for the structures in this work were deposited in the Cambridge Crystallographic Data Centre as supplementary publication number CCDC 1892760-1892762. Copies of the data can be obtained, free of charge, via www.ccdc.cam.ac.uk/conts/ retrieving.html or from the Cambridge Crystallographic Data Centre, CCDC, 12 Union Road, Cambridge CB2 1EZ, UK; fax: +44 1223 336033. E-mail: deposit@ccdc. cam.ac.uk.

Supplementary information (NMR spectra, IR spectra, UV spectra, electrochemical studies, mass spectra) is available free of charge at http://jbcs.sbq.org.br as a PDF file.

\section{Acknowledgments}

The authors are grateful to the Brazilian governmental agencies CNPq (for grants awarded to A. N., A. J. B., A. L. A. and R. A. P.) and to IFSC, INCT-Catálise and FINEP. 
This study was financed in part by the Coordenação de Aperfeiçoamento de Pessoal de Nível Superior, Brasil (CAPES), Finance Code 001.

\section{References}

1. Foresti, R.; Bani-Hani, M. G.; Motterlini R.; Intensive Care Med. 2008, 34, 649.

2. Motterlini, R.; Otterbein, L. E.; Nat. Rev. Drug Discovery 2010, 9, 728 .

3. Kim, H. P.; Ryter, S. W.; Choi, A. M.; Annu. Rev. Pharmacol. Toxicol. 2006, 46, 411.

4. Fukuto, J. M.; Carrington, S. J.; Tantillo, D. J.; Harrison, J. G.; Ignarro, L. J.; Freeman, B. A.; Chen, A.; Wink, D. A.; Chem. Res. Toxicol. 2012, 25, 769.

5. Otterbein, L. E.; Bach, F. H.; Alam, J.; Soares, M.; Lu, H. T.; Wysk, M.; Davis, R. J.; Flavell, R. A.; Choi, A. M.; Nat. Med. 2000, 6, 422.

6. Mann, B. E.; Motterlini, R.; Chem. Commun. 2007, 45, 4818.

7. Ryter, S. W.; Choi, A. M. K.; Am. J. Respir. Cell Mol. Biol. 2009, 41, 251.

8. Blumenthal, I.; J. R. Soc. Med. 2001, 94, 270.

9. Garcia-Gallego, S.; Bernardes, G. J. L.; Angew. Chem., Int. Ed. 2014, 53, 9712.

10. Bauer, I.; Pannen, B. H.; Crit. Care 2009, 13, 220.

11. Mann, B. E.; Organometallics 2012, 31, 5728.

12. Romão, C. C.; Blättler, W. A.; Seixas, J. D.; Bernardes, G. J. L.; Chem. Soc. Rev. 2012, 41, 3571.

13. Schatzschneider, U.; Br. J. Pharmacol. 2015, 172, 1638.

14. Fris, S. D.; Taaning, R. H.; Lindhardt, A. T.; Skrydstrup, T.; J. Am. Chem. Soc. 2011, 133, 18114.

15. Antony, L. A. P.; Slanina, T.; Sebej, P.; Solomek, T.; Klán, P.; Org. Lett. 2013, 15, 4552.

16. Rimmer, R. D.; Richter, H.; Ford, P. C.; Inorg. Chem. 2010, 49, 1180.

17. Seixas, J. D.; Mukhopadhyay, A.; Santos-Silva, T.; Otterbein, L. E.; Gallo, D. J.; Rodrigues, S. S.; Guerreiro, B. H.; Gonçalves, A. M. L.; Penacho, N.; Marques, A. R.; Coelho, A. C.; Reis, P. M.; Romão, M. J.; Romão, C. C.; Dalton Trans. 2013, 42, 5985.

18. Romanski, S.; Rucker, H.; Stamellou, E.; Guttentag, M.; Neudorfl, J.-M.; Alberto, R.; Amslinger, S.; Yard, B.; Schmalz, H.-G.; Organometallics 2012, 31, 5800.

19. Bischof, C.; Joshi, T.; Dimri, A.; Spiccia, L.; Schatzschneider, U.; Inorg. Chem. 2013, 52, 9297.
20. Pierri, A. E.; Pallaoro, A.; Wu, G.; Ford, P. C.; J. Am. Chem. Soc. 2012, 134, 18197.

21. Jimenez, J.; Chakraborty, I.; Mascharak, P. K.; Eur. J. Inorg. Chem. 2015, 30, 5021.

22. Clark, J. E.; Naughton, P.; Shurey, S.; Green, C. J.; Johnson, T. R.; Mann, B. E.; Foresti, R.; Motterlini, R.; Circ. Res. 2003, 93, e2.

23. Chakraborty, I.; Carrington, S. J.; Roseman, G.; Mascharak, P. K.; Inorg. Chem. 2017, 56, 1534.

24. Johnson, T. R.; Mann, B. E.; Teasdale, I. P.; Adams, H.; Foresti, R.; Green, C. J.; Motterlini, R.; Dalton Trans. 2007, 1500.

25. Rimmer, R. D.; Pierri, A. E.; Ford, P. C.; Coord. Chem. Rev. 2012, 256, 1509.

26. Wright, M. A.; Wright, J. A.; Dalton Trans. 2016, 45, 6801.

27. Motterlini, R.; Clark, J. E.; Foresti, R.; Sarathchandra, P.; Mann, B. E.; Green, C. J.; Circ. Res. 2002, 90, e17.

28. Meister, K.; Niesel, J.; Schatzschneider, U.; Schmidt, D. A.; Metzler-Nolte, N.; Havenith, M.; Angew. Chem., Int. Ed. 2010, 49, 3310.

29. Jimenez, J.; Chakraborty, I.; Dominguez, A.; Martinez-Gonzalez, J.; Sameera, W. M. C.; Mascharak, P. K.; Inorg. Chem. 2018, 57, 1766.

30. Berends, H. M.; Kurz, P.; Inorg. Chim. Acta 2011, 380, 141.

31. Sachs, U.; Schaper, G.; Winkler, D.; Kratzert, D.; Kurz, P.; Dalton Trans. 2016, 45, 17464.

32. Aime, S.; Calabi, L.; Cavallotti, C.; Gianolio, E.; Giovenzana, B. G.; Losi, P.; Maiocchi, A.; Palmisano, G.; Sisti, M.; Inorg. Chem. 2004, 43, 7588.

33. Appel, M. A. C.; Hagel, R.; Russel, W. S.; Tetard, D.; WO pat. 01/85717 A1 2001.

34. Gagne, R. R.; Koval, C. A.; Lisensky, G. C.; Inorg. Chem. 1980, 19, 2854.

35. Atkin, A. J.; Lynam, J. M.; Moulton, B. E.; Sawle, P.; Motterlini, R.; Boyle, N. M.; Pryce, M. T.; Fairlamb, I. J. S.; Dalton Trans. 2011, 40, 5755 .

36. Mede, R.; Hoffmann, P.; Klein, M.; Görls, H.; Schmitt, M.; Neugebauer, U.; Gessner, G.; Heinemann, H. S.; Popp, J.; Westerhausen, M.; Z. Anorg. Allg. Chem. 2017, 643, 2057.

37. Chakraborty, I.; Carrington, S. J.; Mascharak, P. K.; Acc. Chem. Res. 2014, 47, 2603.
Submitted: April 21, 2019

Published online: August 6, 2019 